Editorial

\title{
Anteversión femoral y rotación tibial en inestabilidad rotuliana: ¿Cuándo y cómo tratarlas?
}

\section{Femoral Anteversion and Tibial Rotation in Patellar Instability: When and How to Treat it?}

\author{
Rafael Calvo R. ${ }^{1}$ Dra María Jesús Tuca ${ }^{2}$ \\ ${ }^{1}$ Departamento de Ortopedia y Traumatología, Facultad de Medicina \\ Clínica Alemana Universidad del Desarrollo, Vitacura, Santiago, Chile \\ 2 Departamento de Traumatología, Hospital Clínico Mutual de \\ Seguridad C.Ch.C, Santiago, Chile \\ Rev Chil Ortop Traumatol 2018;59:93-94.
}

La evaluación de la anteversión femoral, torsión tibial y valgo de la extremidad no está en las consideraciones iniciales en la inestabilidad rotuliana. El ignorar o no tratar esas alteraciones, es sin duda un causal de fallo en el tratamiento y recidiva de la inestabilidad.

Muchas veces cuesta tomar la decisión de realizar ese tipo de correcciones, dado la complejidad del tratamiento o la no aceptación por parte del paciente, por lo que significa la cirugía y su postoperatorio.

La excesiva anteversión femoral y rotación tibial externa son variables que debemos considerar en el enfrentamiento de la inestabilidad rotuliana. Como evaluarlas y cuando tratarlas son el tema que queremos plantear.

La inestabilidad patelofemoral es una patología frecuente y potencialmente secuelante. La incidencia reportada para un primer episodio de luxación patelar es de $6 \times 100.000$ que se eleva hasta $30 \times 100.000$ en pacientes entre 10 y 17 años. Las tasas de recurrencia tras el tratamiento conservador de un primer episodio oscilan entre el 15\% y el $50 \%$ según el grupo etario y factores predisponentes, y hasta un $50 \%$ evoluciona con dolor, y síntomas mecánicos que impiden el reintegro deportivo.

La luxación patelar es un problema multifactorial, donde la congruencia articular queda determinada por la alineación de la extremidad, la morfología ósea de tróclea y patela, y la interacción entre los restrictores ligamentarios estáticos y musculares dinámicos. Los factores predisponentes de inestabilidad patelar han sido ampliamente estudiados en la literatura, siendo los más relevantes la patela alta, la displasia troclear, el tilt patelar, el TT-TG aumentado, la insuficiencia del vasto medial oblicuo, la rotura o elongación del LPFM, la hiperlaxitud, la excesiva anteversión femoral y rotación tibial externa. La clave para un tratamiento exitoso es estudiar cada una de esas variables, y ponderar la influencia que tienen en la inestabilidad patelar de nuestros pacientes. Incluso se han reportado rangos que apuntan a estimar el riesgo de recurrencia, como el PISS Score (Patela Instability Severity Score), que incluye la edad $<16$ años, la inestabilidad bilateral, la displasia troclear, la patela alta y el tilt patelar. Esas son las variables consideradas como factores de riesgo primarios.

Las alteraciones rotacionales por otra parte, como la excesiva AVF, no son predisponentes primarios, y resulta infrecuente que sean el factor determinante en una inestabilidad patelofemoral. Sin embargo, los estudios de cohorte han mostrado diferencias significativas en la AVF medida en pacientes con inestabilidad patelar versus controles sanos. Esas alteraciones suelen ser menos evidentes al examen físico e imágenes, por lo que pueden pasar desapercibidas y ser subdiagnosticadas si no las sospechamos y buscamos dirigidamente.

\section{¿Qué es la Anteversión Femoral y cómo Estudiarla?}

La AVF se refiere al ángulo de rotación del fémur proximal respecto de su porción distal, definida por una línea que va por el eje del cuello femoral y una tangente a los cóndilos femorales posteriores. Resulta fácil de estimar al examen físico, midiendo las rotaciones interna y externa de la cadera en prono, lo cual tiene una alta correlación con las mediciones imagenológicas.

Copyright $\odot 2018$ by Thieme Revinter Publicações Ltda, Rio de Janeiro, Brazil

License terms \author{
10.1055/s-0039-1677831. \\ ISSN 0716-4548. \\ DOI https://doi.org/
}

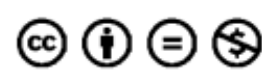


Se considera normal aquellos pacientes con una rotación interna menor a $60^{\circ}$ y externa de al menos $30^{\circ}$. Ante las alteraciones del examen físico, debemos confirmar $\mathrm{y}$ cuantificar el perfil rotacional con imágenes. La tomografía es el gold standard a la fecha, y ha sido ampliamente validado, es de fácil acceso y posee menores costos, pero sus cortes transversales son menos precisos para medir el eje oblicuo del cuello femoral. La resonancia en cambio, tiene mayores costos y menor disponibilidad, pero no produce radiación y su medición de la AVF es más fidedigna ya que sus cortes son oblicuos en la dirección del cuello femoral. No está claramente definido el valor normal de AVF, los reportes son discordantes y con amplia dispersión, sin embargo, hay cierto consenso en la literatura para considerar normal AVF menores a $20^{\circ}$.

\section{¿Por qué es Considerada como una Variable Predisponente de Inestabilidad Patelar?}

Una AVF normal traduce una cadera centrada, con un ángulo neutro de progresión de la marcha. Una excesiva AVF requiere una rotación interna de la extremidad para centrar la cadera, lo que conlleva a una medialización de la troclea respecto a la patela. Eso traduce un aumento del ángulo $\mathrm{Q}$ que refleja el vector lateralizante sobre la patela. Si a eso le sumamos un aumento de la torsión tibial externa, conocido como Malalineamiento Miserbale, se exacerba el desbalance, aumentando el vector lateralizante sobre la patela.

Es por ello que si bien la AVF es un predisponente menos frecuente que la displasia o la patela alta, su incidencia no es despreciable, por lo que debemos buscarla para poder identificar aquellos pacientes en que la excesiva AVF es un factor preponderante. Dados los efectos biomecánicos de una excesiva AVF sobre la articulación patelofemoral, subestimar su importancia puede arriesgar los resultados del tratamiento. Reportes sobre las causas de fallo tras una reconstrucción de LPFM aislada, lo atribuyen hasta en un $11 \%$ de los casos a una excesiva AVF no tratada. ¿Cuál es el punto de corte para definir una AVF excesiva? No está claramente establecido, sin embargo, hay cierto consenso en considerar una versión patológica sobre los $25^{\circ}-30^{\circ}$.

\section{¿Cómo Tratarlas?}

Las osteotomías desrotadoras permiten corregir la anteversión femoral a valores normales. Pueden realizarse en tres niveles, sin que la literatura muestre una clara superioridad de una técnica por sobre la otra. Las osteotomías a nivel del fémur proximal requieren un abordaje en la cadera, pero tiene la ventaja de corregir en el lugar de la deformidad y generar un efecto dinámico al movilizar el cuádriceps a medial. Las osteotomías diafisiarias con clavo enomedular, son técnicamente simples y permiten la carga precoz. La osteotomía supracondilea es probablemente la más utilizada. Permite realizar la osteotomia a través de un mismo abordaje a nivel de la rodilla, y la posibilidad de la corrección biplanar si el paciente también requiere corrección del eje coronal. Las series reportadas a la fecha muestran correcciones para AVF mayores a $30^{\circ}$, con excelentes resultados en cuanto a tasas de reluxación, resultados funcionales y escasas complicaciones.

A modo de conclusión, debemos estimar la AVF en todos nuestros pacientes con inestabilidad patelofemoral, ya sea al examen físico o imágenes. Así podremos reconocer aquellos casos en que la alteración rotacional es un factor relevante, y dónde corregirlo será determinante para evitar el fracaso del plan terapéutico. 